\title{
Adsorption of uranium ions on nano-hydroxyapatite and modified by $\mathrm{Ca}$ and $\mathrm{Ag}$ ions
}

\author{
E. Skwarek ${ }^{1}$ A. Gładysz-Płaska ${ }^{1}$ J. B. Choromańska ${ }^{2} \cdot$ E. Broda $^{1}$
}

Received: 15 October 2018 / Revised: 11 February 2019 / Accepted: 16 March 2019 / Published online: 27 March 2019

(c) The Author(s) 2019

\begin{abstract}
Adsorption of uranium ions on nano-hydroxyapatite modified by silver (Ag-HAP) and calcium (Ca-HAP) ions was examined. Composites or studied adsorbents were studied by means of XRD, ASAP and DLS molecules sizes. The Langmuir, Freundlich, and Dubinin-Radushkevich models were applied to describe the adsorption isotherms. The maximum adsorption capacity $\left(q_{m}\right)$ was found to be $8.1 \mathrm{mmol} / \mathrm{g}$ for Ca-HAP and $7.2 \mathrm{mmol} / \mathrm{g}$ for Ag-HAP at $293 \mathrm{~K}$. The mean free energy values evaluated from the D-R model indicated that the adsorption of $\mathrm{U}(\mathrm{VI})$ ions on the adsorbents proceeds as the chemisorption mechanism. The adsorption equilibrium was reached for both sorbents after $120 \mathrm{~min}$. The adsorption kinetics followed the pseudo-second-order model. There were determined basic parameters characterizing the double electrical layer at the nanoHAP/electrolyte and Ag-HAP/electrolyte, Ca-HAP/electrolyte inters faces: density of the surface charge and zeta potential.
\end{abstract}

Keywords Adsorption U(VI) $\cdot$ Electrical double layer $\cdot$ Nano-hydroxyapatite modification

\section{Introduction}

Uranium is the most used elements as a radioactive source. But it is difficult to obtain it due to limited reserves and high costs. So, it is generally produced from seawater, wastes of nuclear plants by recovery and preconcentration. For example, seawater includes $3.3 \mathrm{ppb}$ uranium and this is important amount for recovery studies (Ulusoy 2014). By increasing usage of radioactive elements including uranium as energy source causes spreading of toxic and dangerous chemicals to environment. The main reasons of this contamination are leaks from nuclear plants, accidents, and natural sources. This circumstance threats both human health and environment. A lot of study showed that uranium species mainly exist as uranyl form $\left(\mathrm{UO}_{2}{ }^{2+}\right)$ in the aquatic medium (Keith et al. 2007). These ions can accumulate at organs and tissues by forming stable complexes with various biochemical molecules in the human body. In addition, it causes a lot of negative circumstances like cancer, organ failure, and finally

E. Skwarek

ewunias@hektor.umcs.lublin.pl

1 Faculty of Chemistry, Maria Curie-Sklodowska University, M. Curie-Sklodowska Sq. 3, 20-031 Lublin, Poland

2 Department of Rehabilitation, Medical University of Warsaw, S. Banacha str.1a, 02-097 Warsaw, Poland death. So, removal of uranium species is very important and attracts great attention due to their negative effects on the human health (Gilman et al. 1998). Most used conventional methods for recovery or pre-concentration of uranium species are adsorption (Şimşek et al. 2017), biological accumulation precipitation and membrane filtration. Among these approaches, adsorption is mostly preferred in last decades owing to positive advantages. In the adsorption, ion or molecules in the solution or gas phase are retained on a solid surface through physical or chemical interaction. Mechanism of adsorption is fairly complex, but it is very useful method with easy applications. Especially, if the concentration of target species is very low and so recovery of these species is so expensive and laborious with conventional methods, the adsorption is first preference method with simplicity, cost effectivity, and environmental friendly. So, it is one of the most studied research areas for removal of toxic species.

Nano-hydroxyapatite $\left[\mathrm{Ca}_{10}(\mathrm{OH})_{2} \cdot\left(\mathrm{PO}_{4}\right)_{6}\right]$ plays a significant role in both isolation of dissolved metals and their transformation in soil into less soluble phases. The literature presents the papers on strong affinity of hydroxyapatite for strontium and other metals (Janusz and Skwarek 2016; Skwarek and Janusz 2016; Skwarek 2015). Hydroxyapatite is an ideal material for long-term binding of contaminates due to its high sorption capacity for the actinide series and heavy metals, poor solubility in water, high stability under 
reducing and oxidizing conditions, accessibility, and low preparation cost.

The investigation proposed in this paper will include measurements of uranyl ions adsorption at the nanohydroxyapatite and its modification/electrolyte solution interface by means of spectroscopy method. The other aim of the paper, closely connected with the adsorption process, is determination of the parameters characterizing the structure of double electrical layer formed at the nanohydroxyapatite and its modification/ electrolyte interface in the presence of uranyl ions.

\section{Materials and methods}

The studies of nano-hydroxyapatite obtained by the wet method were carried out. In order to prepare reaction substrates, there were made $1 \mathrm{~mol} / \mathrm{dm}^{3}$ solutions of the following reagents: $\mathrm{Ca}(\mathrm{OH})_{2}$ calcium hydroxide, $95 \%$ purity of the Aldrich firm, $\mathrm{H}_{3} \mathrm{PO}_{4}$-ortophosphoric acid (V), $85 \%$ purity of the POCh firm. Hydroxyapatite powder was obtained by titration of $180 \mathrm{~cm}^{3}$ of hydroxide suspension with phosphoric acid (V) solution pH9.2 were obtained. The procedure was repeated three times: on the average about $92 \mathrm{~cm}^{3}$ of $\mathrm{H}_{3} \mathrm{PO}_{4}$ was used. The obtained sediments were washed many times with redistilled water and centrifuged till the constant value of conductivity of the solution from over precipitates was obtained and then dried at $80{ }^{\circ} \mathrm{C}$ for $24 \mathrm{~h}$. The studied samples were designated as follows: pure nanohydroxyapatite nano-HAP, hydroxyapatite with the excess of phosphorus Ag-HAP (Skwarek 2016), with the carbon ions Ca-HAP built into the structure.

Surface properties of nano-hydroxyapatite and its modifications were studied by means of X-ray diffraction (XRD), and adsorption-desorption of nitrogen (ASAP 2405 type Accelerated Surface Area and Porosimetry by the Micromeritics Instruments, Co firm.). The XRD radiation diffraction was studied by means of a diffractometer equipped with a rtg generator of the ISO-DEBYFLEX 303-60 kV type produced by the Seifert Analytical X-ray firm and a cooling system KMW 3000C produced by the Oxford Diffraction firm. The measurement data were collected, analysed and processed using the XRAYAN program.

Physicochemical properties chracteristic of electrical double layer of nano-hydroxyapatite $\left[\mathrm{Ca}_{10}(\mathrm{OH})_{2}\left(\mathrm{PO}_{4}\right)_{6}\right]$ and its modificated surface were studied by means of potentiometric titration and electrophoretic measurements. Surface charge measurements were performed simultaneously in the suspension of the same solid content, to keep the identical conditions of the experiments in a thermostated Teflon vessel at $298.15 \mathrm{~K}$. To eliminate the influence of $\mathrm{CO}_{2}$ all potentiometric measurements were made under nitrogen atmosphere. $\mathrm{pH}$ values were measured using a set of glass REF 451 and calomel pHG201-8 electrodes with the Radiometer assembly. Surface charge density was calculated from the difference of the amounts of added acid or base to obtain the same $\mathrm{pH}$ value of suspension as for the background electrolyte. As a background electrolyte $\mathrm{NaNO}_{3}$ solution was used at the concentrations $0.1,0.01$ and $0.001 \mathrm{~mol} / \mathrm{dm}^{3}$. The surface charge density and zeta potential were measured for the background electrolyte $\mathrm{NaNO}_{3}$ concentration $\left(0.001 \mathrm{~mol} / \mathrm{dm}^{3}\right)$ as a function of $\mathrm{pH}$ and concentration of the uranyl ions ranged from 0.01 to $0.000001 \mathrm{~mol} / \mathrm{dm}^{3}$. The zeta potential and size particles were determined by electrophoresis with Zetasizer 3000 by Malvern. The measurements were performed at $100 \mathrm{ppm}$ solid concentration ultrasonication of the suspension. The average size of particles of studied compounds was determined by Zetasizer 3000 was as follows: $\mathrm{HAP}=30 \mathrm{~nm}, \mathrm{Ag}-\mathrm{HAP}=47 \mathrm{~nm}$, and $\mathrm{Ca}-\mathrm{HAP}=72 \mathrm{~nm}$. The parameters of porous structure of nano-hydroxyapatites were determined using the standard method which is low-temperature nitrogen adsorption/desorption. The measurements were made after samples degassing at reduced pressure.

\section{Sorption experiments}

\subsection{Batch adsorption procedure}

The experiments were conducted in $100 \mathrm{~cm}^{3}$ Erlenmeyer flasks containing $10 \mathrm{mg}$ of sorbent and $50 \mathrm{~cm}^{3}$ of uranium solution to determine the effect of initial metal ion concentration. A series of flasks, with the initial metal concentrations from 0.5 to $20 \mathrm{mmol} / \mathrm{dm}^{3}$ was shaken on a shaker incubator for $6 \mathrm{~h}$ at 293,313 and $333 \mathrm{~K}$. The initial concentrations of uranium in the case of kinetic study were $0.5 \mathrm{mmol} / \mathrm{dm}^{3}$. After stirring the solutions were filtered, centrifuged and the percentage of uranium adsorbed by the hydroxyapatite sorbent was determined from the difference between the initial $\mathrm{C}_{\text {in }}$ and the equilibrium $\mathrm{C}_{\mathrm{eq}}$ concentrations of uranium in the aqueous solution before and after the contact. The initial and equilibrium concentrations of the aqueous solutions were determined by the spectrophotometric method using Arsenazo III as a chromogenic agent at a wavelength of $650 \mathrm{~nm}$ (Marczenko and Balcerzak 1998). The adsorption capacity $\mathrm{q}_{\mathrm{e}}(\mathrm{mmol} / \mathrm{g}$ ) and adsorption percentage (A) were calculated based on Eqs. (1) and (2):

$q_{e}=\frac{\left(c_{i n}-c_{e q}\right) \times V}{M \times m}$,

$\mathrm{A}(\%)=\frac{\left(c_{i n}-c_{e q}\right)}{c_{i n}} \times 100 \%$,

where $c_{i n}, c_{e q}$ denote the initial and equilibrium uranium concentrations $\left(\mathrm{mmol} / \mathrm{dm}^{3}\right)$, respectively, $V$ is the solution volume $\left(\mathrm{dm}^{3}\right)$ and $m$ refers to the mass of adsorbent (mg), $M$ is the molar mass $(\mathrm{g} / \mathrm{mol}), A \%$ is the adsorption percentage of uranium. 


\subsection{Mathematical calculation of the adsorption parameters}

\subsubsection{Kinetic models}

The sorption kinetic data of uranium on the adsorbent studied was analyzed in terms of the pseudo-first order and pseudo-second order rate equation (Yusan and Erenturk 2010). The linearized form of the pseudo-first order rate equation is given as:

$\log \left(q_{e q}-q_{t}\right)=\log q_{e q}-\left(\frac{k_{1}}{2.303}\right) \times t$

The linearized form of the pseudo-second order rate equation is given as:

$\frac{t}{q_{t}}=\frac{1}{k_{2} q_{e q}^{2}}+\left(\frac{t}{q_{e q}}\right)$

where $q_{e q}$ and $q_{t}$ are the amounts of uranium ions adsorbed at equilibrium in $\mathrm{mmol} / \mathrm{g}$, and at time $t$ in $\mathrm{min}$, respectively, and $k_{1}$ is the pseudo-first-order rate constant $(1 / \mathrm{min}), k_{2}(\mathrm{~g} /$ $\mathrm{mmol} \mathrm{min}$ ) is the second-order rate constant of adsorption.

\subsubsection{Adsorption isotherm models}

The data for the uranium uptake at different temperatures were processed in accordance to the linearized form of the Langmuir, Freundlich and Dubinin-Radushkevich model (D-R) isotherm equations.

The Langmuir equation : $\frac{c_{e q}}{q_{e q}}=\frac{1}{q_{m} K_{L}}+\frac{c_{e q}}{q_{m}}$

The Freundlich equation : $\log q_{e q}=\frac{1}{n \log c_{e q}}+\log K_{F}$

TheDubinin - Radushkevichequation : $\ln q_{e q}=\ln q_{m}-\beta \varepsilon^{2}$

where: $c_{e q}$ denotes the equilibrium concentrations of $\mathrm{U}(\mathrm{VI})$ in the aqueous phases $\left(\mathrm{mmol} / \mathrm{dm}^{3}\right), q_{m}(\mathrm{mmol} / \mathrm{g})$ is the maximum sorption capacity $K_{L}\left(\mathrm{dm}^{3} / \mathrm{mmol}\right)$ is the Langmuir isotherm constant, $n, K_{f}$ are the Freundlich constants, $\beta$ is the activity coefficient related to the adsorption mean free energy $\left(\mathrm{mol}^{2} / \mathrm{kJ}^{2}\right)$, and $\varepsilon$ relates to the Polanyi potential $\left(\varepsilon=R T \ln \left(1+\frac{1}{c_{e q}}\right)\right)$. The adsorption free energy $\left(\mathrm{E}_{\mathrm{n}}\right)$ can be calculated as:

$$
E_{n}=\frac{1}{\sqrt{-2 \beta}}
$$

\subsubsection{Thermodynamic study}

The thermodynamic parameters of the uranium adsorption, can be determined using the equilibrium constant $\mathrm{K}_{\mathrm{d}}=\mathrm{q}_{\mathrm{e}} /$ $\mathrm{c}_{\mathrm{eq}}$, which depends on temperature. The change in the free energy $\Delta \mathrm{G}^{0}(\mathrm{~kJ} / \mathrm{mol})$, standard enthalpy $\Delta \mathrm{H}^{0}(\mathrm{~kJ} / \mathrm{mol})$ and entropy $\Delta \mathrm{S}^{0}(\mathrm{~kJ} /(\mathrm{mol} \cdot \mathrm{K}))$, associated with the adsorption process was calculated from the Van't Hoff Eq. (9):

$\Delta G^{0}=-R T \ln K_{d}$

$\ln K_{d}=\frac{\Delta S^{0}}{R}-\frac{\Delta H^{0}}{R T}$

where $\mathrm{R}$ is the universal gas constant $(8.314 \mathrm{~J} / \mathrm{mol} \mathrm{K})$ and $\mathrm{T}$ is the temperature $(\mathrm{K})$. The $\Delta \mathrm{H}^{0}$ and $\Delta \mathrm{S}^{0}$ parameters were calculated from the slope and intercept of the plot $\ln _{\mathrm{d}}$ as a function of $1 / \mathrm{T}$.

\section{Results and discussion}

The XRD data confirms phase purity of the studied samples Fig. 1. Peak characteristic of crystal form of nanohydroxyapatite, i.e., peaks and their intensities occurring at the angles $2 \theta 25.9-35 \% ; 31.75-100 \% ; 32.96-55 \%$; $39.84-20 \%$; 46.7-40\%; 49.5-30\%, can be observed. This is in agreement with the phase analysis made from the ASTM data. As follows from the XRD analysis after U(VI) adsorption on the nano-hydroxyapatite surface, there is formed a new compound calcium uranyl phosphate hydrate $\mathrm{Ca}\left(\mathrm{UO}_{2}\right)_{2}\left(\mathrm{PO}_{4}\right)_{2}\left(\mathrm{H}_{2} \mathrm{O}\right)_{11}$ on the surface in the amount of

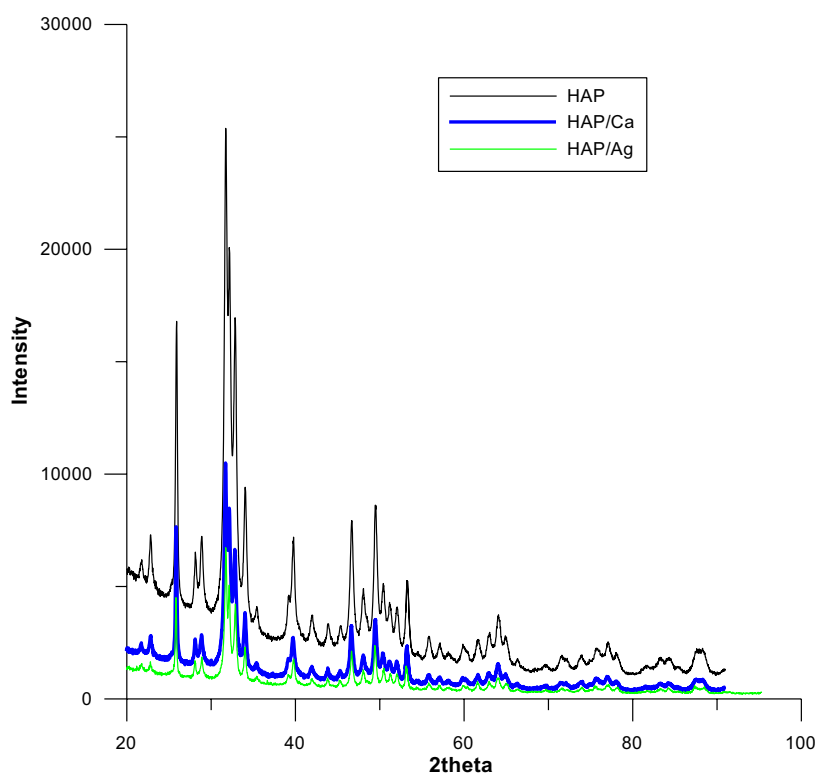

Fig. 1 X-ray diffraction of nano-hydroxyapatite sample and its modification with adsorbed uranyl nitrate 
Table 1 Chosen structural parameters Ca-HAP and Ca-HAP/U(VI)

\begin{tabular}{|c|c|c|c|c|c|c|}
\hline & $\mathrm{Ca}-\mathrm{HAP}$ & $\mathrm{Ca}-\mathrm{HAP} / \mathrm{U}(\mathrm{VI})$ & Ag-HAP & $\mathrm{Ag}-\mathrm{HAP} / \mathrm{U}(\mathrm{VI})$ & HAP & $\mathrm{HAP} / \mathrm{U}(\mathrm{VI})$ \\
\hline BET surface area $\left(\mathrm{m}^{2} / \mathrm{g}\right)$ & 54 & 53 & 55 & 53 & 105 & 25 \\
\hline Langmuir surface area $\left(\mathrm{m}^{2} / \mathrm{g}\right)$ & 79 & 77 & 80 & 78 & 134 & 37 \\
\hline $\begin{array}{l}\text { BJH cumulative adsorption surface area of pores } \\
\text { between } 1.7 \text { and } 300 \mathrm{~nm} \text { diameter }\left(\mathrm{cm}^{3} / \mathrm{g}\right)\end{array}$ & 0.3 & 0.25 & 0.41 & 0.35 & 0.54 & 0.13 \\
\hline $\begin{array}{l}\text { BJH cumulative desorption surface area of pores } \\
\text { between } 1.7 \text { and } 300 \mathrm{~nm} \text { diameter }\left(\mathrm{cm}^{3} / \mathrm{g}\right)\end{array}$ & 0.3 & 0.26 & 0.45 & 0.36 & 0.53 & 0.13 \\
\hline Average pore diameter (4V/A by BET) $[\mathrm{nm}]$ & 22.16 & 23.69 & 23.91 & 26.74 & 17.72 & 20.36 \\
\hline BJH adsorption on average pore diameter (4V/A) (nm) & 22.53 & 23.63 & 25.12 & 28.56 & 18.08 & 20.75 \\
\hline BJH desorption on average pore diameter (4V/A) (nm) & 12.3 & 12.72 & 23.41 & 26.58 & 17.46 & 13.51 \\
\hline
\end{tabular}

$68.9 \%$ but $31 \%$ is nano-hydroxyapatite (Skwarek et al. 2017). XRD studies after U(VI) adsorption did not show any new crystalline form on the surface of Ca-HAP or Ag-HAP, only some differences in the crystallite size were detected by the Scherrer method.The size of crystallites computed using the Scherrer method was nano-HAP $=20 \mathrm{~nm}$; $\mathrm{Ag}-\mathrm{HAP}=18 \mathrm{~nm}$; $\mathrm{Ca}-\mathrm{HAP}=19 \mathrm{~nm}$; nano-HAP/U(VI) $=13.7 \mathrm{~nm} ; \mathrm{Ag}-$ $\mathrm{HAP} / \mathrm{U}(\mathrm{VI})=16 \mathrm{~nm} \mathrm{Ca}-\mathrm{HAP} / \mathrm{U}(\mathrm{VI})=11 \mathrm{~nm}$. It correlates well with the results of adsorption described later, and confirms possibility of using nano-hydroxyapatite for removal of 6-valued uranium from aqueous solutions.

The measurements were made after samples degassing at reduced pressure, and the results are shown in Table 1 in our publication (Skwarek et al. 2017). As follows from the results (Table 1), U(VI) adsorbed on the surface causes multiple decreases in the specific surface area and decrease in the average radius of the pores which may be due to formation of calcium uranyl phosphate hydrate layer on the nano-hydroxyapatite layer as confirmed by the XRD studies. The specific surface area decreases also after U(VI) adsorption for the systems: Ag-HAP and Ca-HAP (Table 1). The volume of pores increases (Table 1) which may be due to formation of $\mathrm{CaCO}_{3}$ that results in $\mathrm{Ca}$ ions escape from the surface of hydroxyapatites causing at the same time a pore volume increase. The amount of $\mathrm{Ca}$ ions is the largest at the surface in the nano-hydroxyapatite structure compared to other elements building it.

Basic experimental parameters of the electrical double layer: $\mathrm{pH}_{\mathrm{PZC}}$ and $\mathrm{pH}_{\mathrm{IEP}}$ were determined in order to study the behaviour of nano-HAP, Ag-HAP and Ca-HAP in the aqueous solution can be seen in Table 2. The decrease $\mathrm{pH}_{\mathrm{PZC}}$ parameter can be observed and compared to the stoichiometric nano-HAP, which can be explained by incorporation of more beside $\mathrm{Ag}$ and $\mathrm{Ca}$ elements into the nano-hydroxyapatite structure which contributes to the increase of $\mathrm{U}(\mathrm{VI})$ ion adsorption.

Figures 2 and 3 presents the dependence of surface charge density on $\mathrm{pH}$. The results indicate that surface charge density decreases with the increasing $\mathrm{pH}$ value
Table 2 Parameter of electrical double layer

\begin{tabular}{lll}
\hline Materials & $\mathrm{pH}_{\mathrm{PZC}}$ & $\mathrm{pH}_{\mathrm{IEP}}$ \\
\hline nano-HAP & 7.2 & $<4$ \\
Ag-HAP & 6.91 & $<4$ \\
Ca-HAP & 6.3 & $<4$ \\
\hline
\end{tabular}

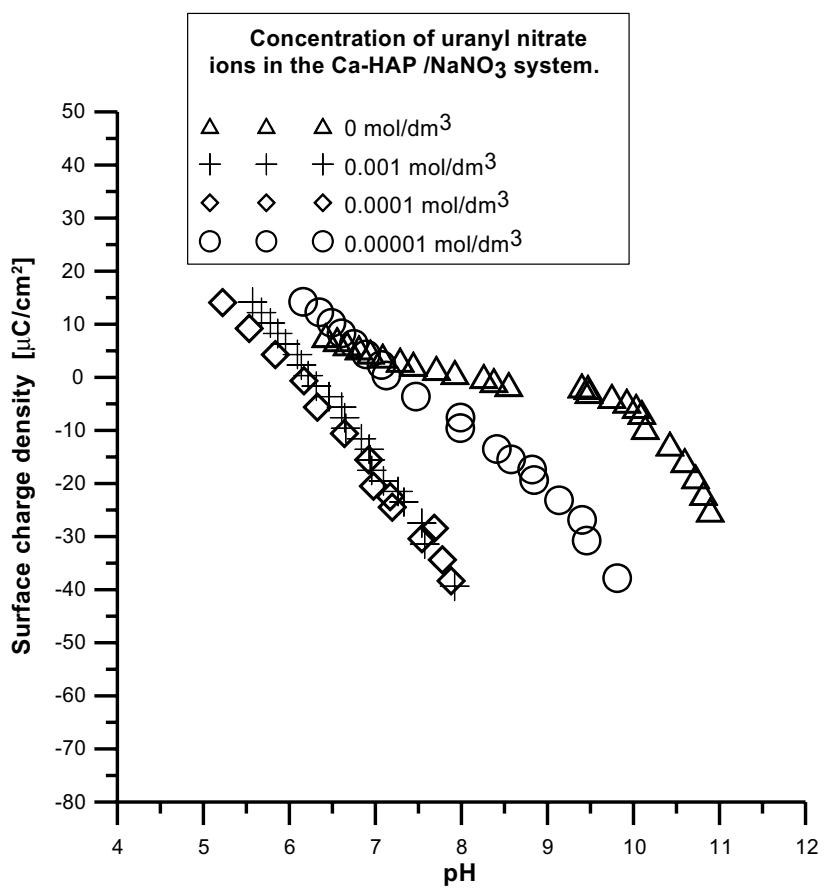

Fig. 2 The surface charge density as a function of $\mathrm{pH}$ for the Ca$\mathrm{HAP}$ (c) dispersed in $\mathrm{NaNO}_{3}$ solution with different concentrations of U(VI)

for all studied concentration and have a negative value in almost whole $\mathrm{pH}$ range. The $\mathrm{pHpzc}$ point changes with the increasing $\mathrm{U}(\mathrm{VI})$ concentration shifting towards acidic value as a result of $\mathrm{U}(\mathrm{VI})$ accumulation on the surface. The discrepancy between $\mathrm{pH}_{\mathrm{pzc}}$ and $\mathrm{pH}_{\mathrm{IEP}}$ for individual samples of the types, nano-HAP, Ag-HAP, and Ca-HAP, 


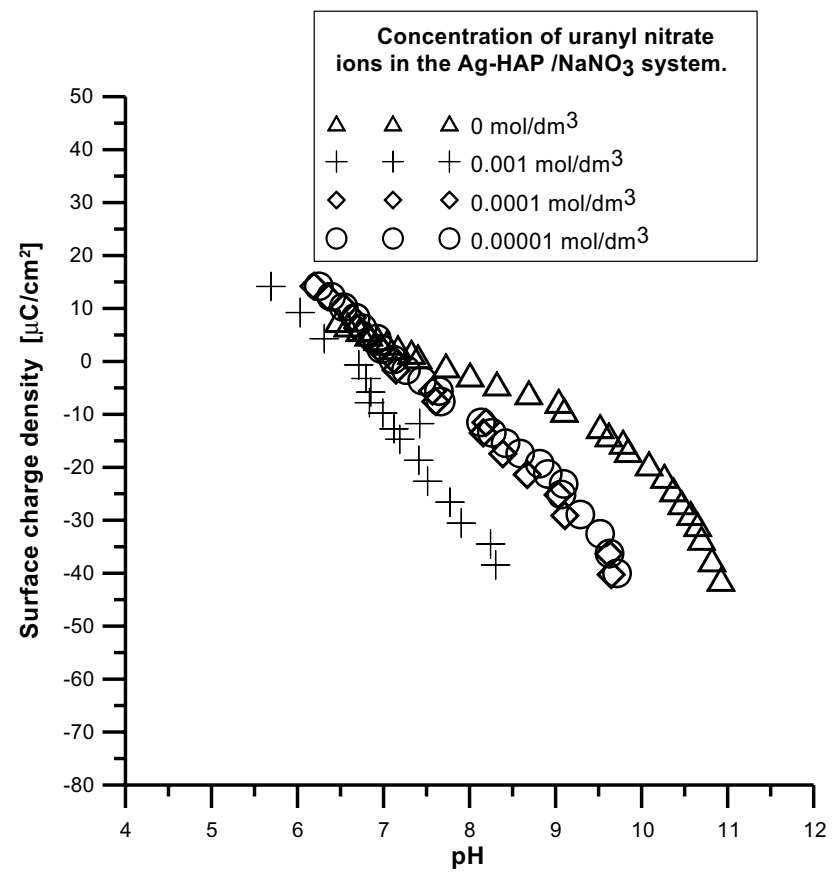

Fig. 3 The surface charge density as a function of $\mathrm{pH}$ for the Ag$\mathrm{HAP}$ (c) dispersed in $\mathrm{NaNO}_{3}$ solution with different concentrations of U(VI)

is caused by determination of surface charge density from the acidic-basic reaction of the surface groups of amphoteric hydroxyl ions and $\mathrm{PO}_{4}{ }^{-3}$ groups of acidic character. Additionally, the zeta potential depends on part of surface charge affected by no uniform absorption or desorption of calcium or phosphate ions.

Dependence of zeta potential on $\mathrm{pH}$ for Ag-HAP and Ca-Hap were determined in $\mathrm{NaNO}_{3}$ of the concentration $0.001 \mathrm{~mol} / \mathrm{dm}^{3}+0.000001 \mathrm{~mol} / \mathrm{dm}^{3} ; 0.00001 \mathrm{~mol} / \mathrm{dm}^{3}$; $0.0001 \mathrm{~mol} / \mathrm{dm}^{3} ; 0.001 \mathrm{~mol} / \mathrm{dm}^{3} \mathrm{U}(\mathrm{VI})$ as shown in Figs. 4 and 5. As follows dependence of zeta potential on $\mathrm{pH}$ in the $\mathrm{Ag}-\mathrm{HAP} / \mathrm{NaNO}_{3} / \mathrm{U}(\mathrm{VI})$ and $\mathrm{Ca}-\mathrm{Hap} / \mathrm{NaNO}_{3} / \mathrm{U}(\mathrm{VI})$ systems with the increasing $\mathrm{pH}$ value, the zeta potential decreases and has negative values that take place in the range of 0 to $-40 \mathrm{mV}$ for the $\mathrm{Ag}-\mathrm{HAP} / \mathrm{NaNO}_{3} / \mathrm{U}(\mathrm{VI})$ and $\mathrm{Ca}-\mathrm{Hap} / \mathrm{NaNO}_{3} / \mathrm{U}(\mathrm{VI})$ systems. Extrapolation of the zeta potential dependence in the $\mathrm{pH}$ function allows to suppose that the value of $\mathrm{pH}_{\text {IEP }}$ is $<4$. The zeta potential is dependent on this part of surface charge which causes that $\mathrm{PO}_{4}{ }^{3-}$ or $\mathrm{Ca}^{2+}$ ions adsorb or desorb at the nanohydroxyapatite/solution interface. U(VI) ions affect the zeta potential value and compared to the initial electrolyte they decrease it zeta potential in the whole $\mathrm{pH}$ range. With the increasing $\mathrm{U}(\mathrm{VI})$ ions concentration the zeta potential decrease was observed. Effect of concentration U(VI) changes on the zeta potential can be seen in Fig. 4 for the Ca-HAP.

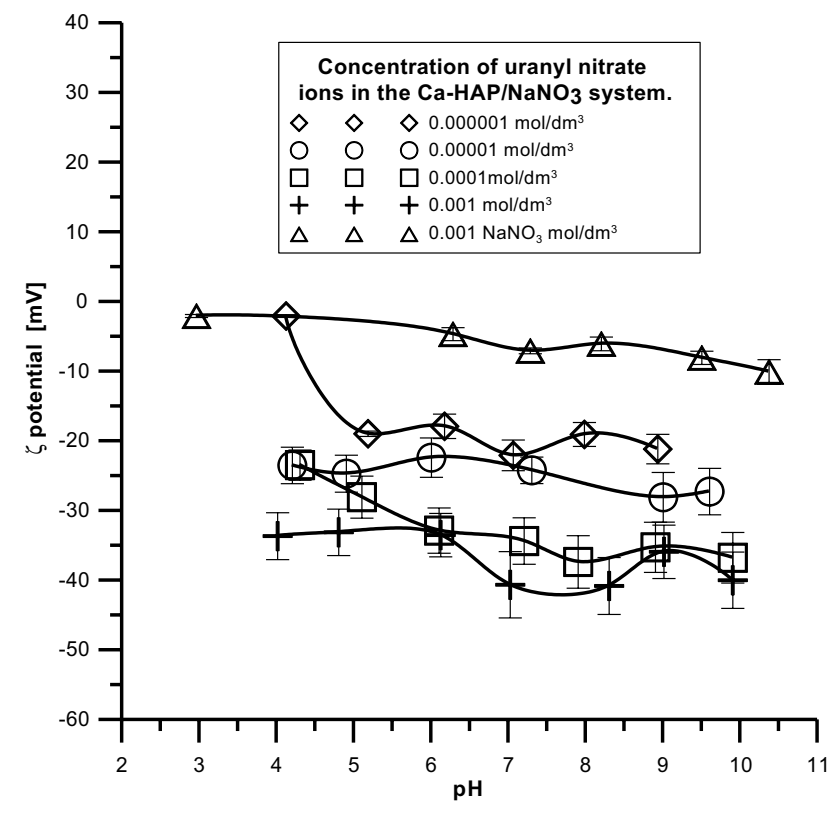

Fig. 4 The zeta potential as a function of $\mathrm{pH}$ for Ca-HAP dispersed in $\mathrm{NaNO}_{3}$ solution with different concentrations of uranyl nitrate ions

\subsection{Effect of contact time and kinetic study}

The effect of contact time was studied at the initial uranium concentration $0.0005 \mathrm{~mol} / \mathrm{dm}^{3}$, the ambient temperature $(293 \mathrm{~K})$. Figure 6 shows a rapid initial uptake rate of uranium from the beginning up to $1 \mathrm{~h}$, and thereafter, the adsorption rate became practically constant. The variation in

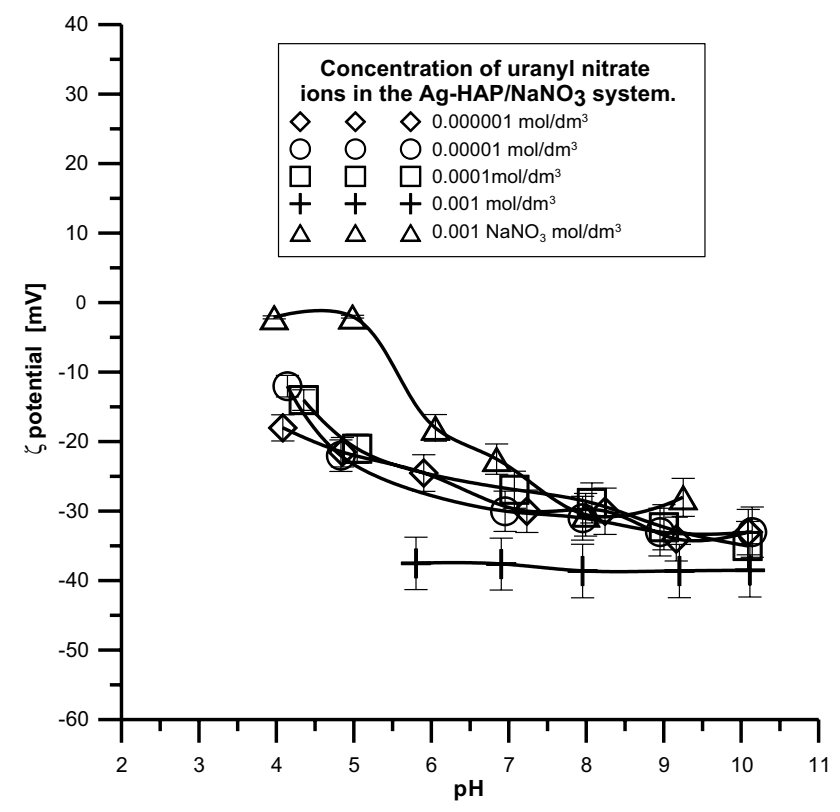

Fig. 5 The zeta potential as a function of $\mathrm{pH}$ for Ag-HAP dispersed in $\mathrm{NaNO}_{3}$ solution with different concentrations of uranyl nitrate ions 
the extent of adsorption may be due to the fact that initially all sites on the sorbent surface were vacant and the solute concentration gradient was relatively high.

In order to define the kinetics of uranium adsorption, the parameters for the adsorption process were studied for the contact time ranging from 0.5 to $25 \mathrm{~h}$, by monitoring the removal percent removal of uranium using the hydroxyapatite adsorbents. The results presented in Fig. 6 show that the removal rate of $\mathrm{U}(\mathrm{VI})$ ions was extremely rapid in the first $30 \mathrm{~min}$. The sorption equilibrium was achieved after $120 \mathrm{~min}$. The kinetic data was fitted to the Lagergren pseudofirst order model and Ho pseudo-second order kinetic model. The kinetic rate constants obtained from the first order and second order pseudo-kinetic models are given in Table 3. Though, the pseudo-second order kinetics possesses high correlation coefficient value which is greater than that of the pseudo-first order one (Sherman et al. 2008). Thus, it can be concluded that uranium sorption on hydroxyapatite seems to be more pseudo-second order (Pang et al. 2010). According to Ho and McKay (1999) in the adsorption processes following the pseudo-second-order model, the mechanism of adsorption proceeds mainly by chemisorption.

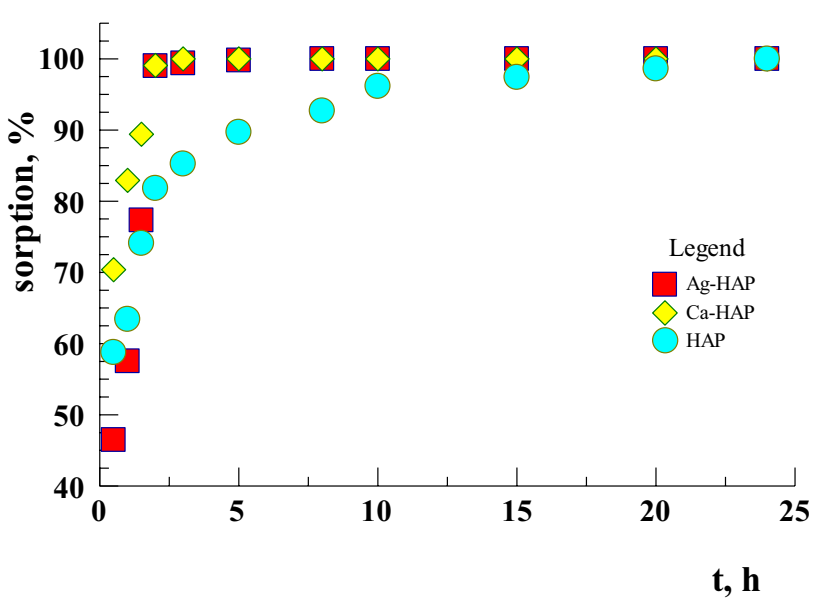

Fig. 6 The time influence on uranium sorption on the Ag-HAP, CaHAP and HAP sorbent $\left(293 \mathrm{~K} ; \mathrm{c}_{\mathrm{in}} \mathrm{U}(\mathrm{VI})=0.5 \mathrm{mmol} / \mathrm{dm}^{3} ; \mathrm{pH}=6\right)$

\subsection{Adsorption isotherms}

In order to describe the uranium uptake by the hydroxyapatite sorbent, the isotherm data were analyzed using the three models, Langmuir, Freundlich and Dubinin-Redushkevich (D-R) (Sun et al. 2010). The isotherm profiles of uranium adsorption at various temperatures are shown in Fig. 7. The Langmuir isotherm equation is valid for the monolayer sorption on the surface containing a finite number of identical sorption sites. The Freundlich equation is based on the adsorption of heterogeneous surfaces. This equation does not provide any information about the maximum capacity of adsorption contrary to the Langmuir model. The Dubinin-Radushkevich (D-R) isotherm is more general than the Langmuir isotherm because it does not assume a homogeneous surface but gives information about chemical or physical adsorption (Liu et al. 2010; Sprynsky et al. 2010).

By comparing the correlation coefficients (Table 4), it can be concluded that the Langmuir isotherm provides a good model for the sorption system. The maximum adsorption capacity of uranium found using the Langmuir model was $7.2 \mathrm{mmol} / \mathrm{g}$ for $\mathrm{Ag}-\mathrm{HAP}$ and $8.1 \mathrm{mmol} / \mathrm{g}$ for Ca-HAP at $293 \mathrm{~K}$. The value of the free energy estimated from the DR model $\mathrm{E}>8 \mathrm{~kJ}$ indicated that the adsorption process is of chemical nature. The hydroxyapatite sorbent and its modification (Ag-HAP and Ca-HAP) has a high adsorption capacity, much higher than that of other sorbents. The theoretical sorption capacities determined by the Langmuir model are very high. This may be a result of the fact that precipitation of mainly uranyl phosphates on the surface plays a decisive role in the sorption process. According to the literature data concentration of uranium in the solution contacted with hydroxyapatite is also a very important factor. If the $\mathrm{g} \mathrm{U} / \mathrm{g}$ HAP ratio is greater than 0.0011, that is high (Arey et al. 1999) uranium concentrations are found in the solution, then the precipitation of $\mathrm{H}_{2}\left(\mathrm{UO}_{2}\right)_{2}\left(\mathrm{PO}_{4}\right)_{2} \cdot 10 \mathrm{H}_{2} \mathrm{O}$ or $\mathrm{Ca}\left(\mathrm{UO}_{2}\right)_{2}\left(\mathrm{PO}_{4}\right)_{2} \cdot 10-12 \mathrm{H}_{2} \mathrm{O}$ is a dominant mechanism (Eqs. 11, 12) (Taffet 2004). This indicates that the given hydroxyapatite mass can adsorb a greater mass of uranium from the solution by precipitation than by common sorption. In the case of lower concentrations of uranium in the

Table 3 Kinetic parameters for the adsorption of the uranium ions on the Ag-HAP and Ca-HAP sorbent, $\mathrm{R}^{2}$-correlation, [for HAP see (Skwarek et al. 2017)]

\begin{tabular}{llll}
\hline Pseudo-first-order model & $\mathrm{k}_{1}(1 / \mathrm{min})$ & $\mathrm{q}_{\mathrm{e}}$ calc $(\mathrm{mmol} / \mathrm{g})$ & $\mathrm{R}^{2}$ \\
\hline Ag-HAP & 0.000105 & $9.12 \times 10^{-4}$ & 0.5432 \\
Ca-HAP & 0.00368 & $9.7 \times 10^{-4}$ & 0.5263 \\
\hline Pseudo-second-order model & $\mathrm{k}_{2}$ & $\mathrm{q}_{\mathrm{e}}$ calc & $\mathrm{R}^{2}$ \\
& $(\mathrm{~g} / \mathrm{mmol} \mathrm{min})$ & 2.55 & 0.9996 \\
\hline Ag-HAP & 19.92 & 2.52 & 0.9999 \\
Ca-HAP & 59.96 & $2 . \mathrm{g})$ & \\
\hline
\end{tabular}



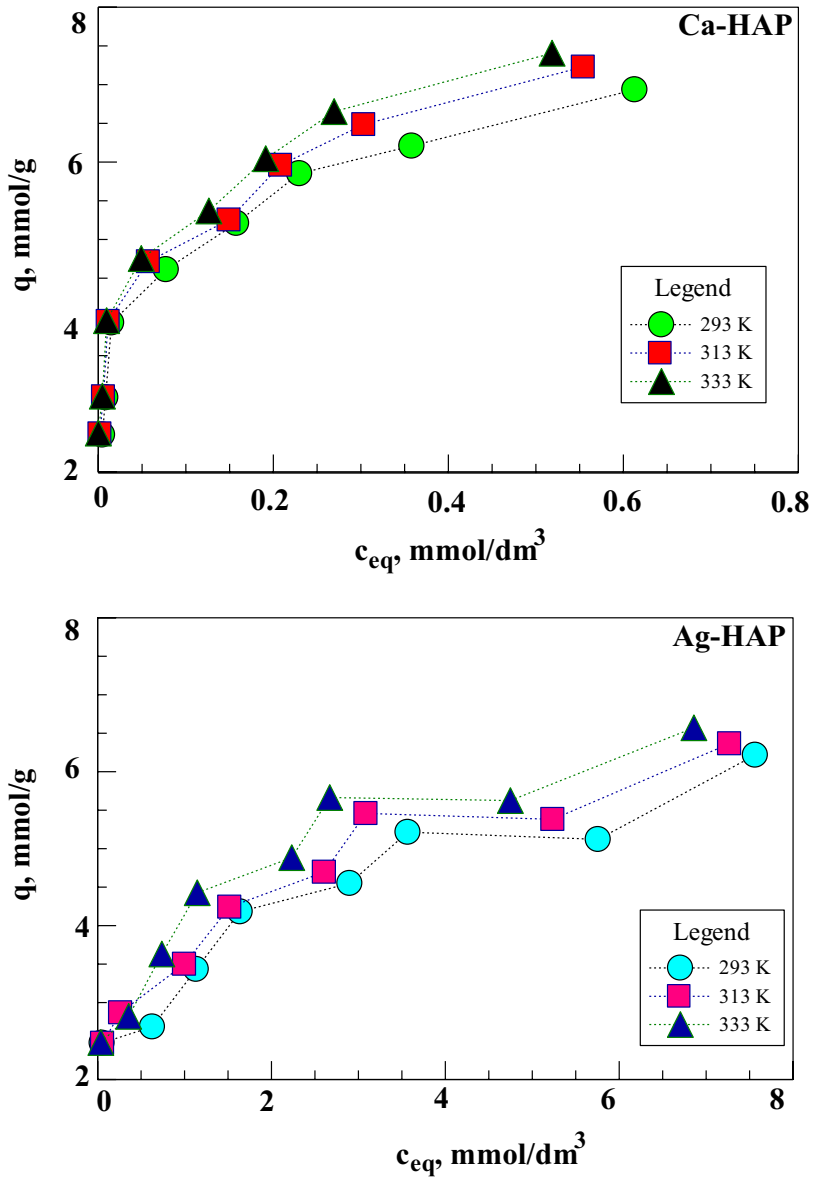

Fig. 7 The isotherms of U(VI) adsorption on the Ca-HAP and AgHAP sorbent $\left(\mathrm{pH}_{\mathrm{in}} 6\right.$; $\mathrm{T}=293 \mathrm{~K}, 313 \mathrm{~K}, 333 \mathrm{~K}$; q- concentration of $\mathrm{U}(\mathrm{VI})$ in the sorbent phase $(\mathrm{mmol} / \mathrm{g}) ; \mathrm{c}_{\mathrm{eq}}$ - equilibrium concentration of $\mathrm{U}(\mathrm{VI})$ in the aqueous phase $\left(\mathrm{mmol} / \mathrm{dm}^{3}\right)$ solution, a great role in the process of hydroxyapatite sorption is played also by other mechanisms such as: sorption (Eqs. 13, 14) or ion exchange (Eq. 15), based on the equations: (Simon et al. 2008).

$\mathrm{Ca}^{2+}+2 \mathrm{UO}_{2}{ }^{2+}+2 \mathrm{PO}_{4}{ }^{3-}+\mathrm{nH}_{2} \mathrm{O} \rightarrow \mathrm{Ca}\left[\left(\mathrm{UO}_{2}\right)\left(\mathrm{PO}_{4}\right)\right]_{2} \cdot \mathrm{nH}_{2} \mathrm{O}$

$2 \mathrm{H}^{+}+2 \mathrm{UO}_{2}{ }^{2+}+2 \mathrm{PO}_{4}{ }^{3-}+\mathrm{nH}_{2} \mathrm{O} \rightarrow \mathrm{H}_{2}\left[\left(\mathrm{UO}_{2}\right)\left(\mathrm{PO}_{4}\right)\right]_{2} \cdot \mathrm{nH}_{2} \mathrm{O}$

$\equiv \mathrm{OH}+\mathrm{UO}_{2}^{2+} \rightarrow \equiv \mathrm{O}-\mathrm{UO}_{2}^{+}+\mathrm{H}^{+}$

$\equiv \mathrm{O}_{3} \mathrm{P}-\mathrm{OH}++\mathrm{UO}_{2}{ }^{2+} \rightarrow \equiv \mathrm{O}_{3} \mathrm{P}-\mathrm{O}-\mathrm{UO}_{2}{ }^{2+}+\mathrm{H}^{+}$

$\equiv \mathrm{Ca}^{2+}+\mathrm{UO}_{2}{ }^{2+} \rightarrow \equiv \mathrm{UO}_{2}{ }^{2+}+\mathrm{Ca}^{2+}$

\subsection{Effect of temperature}

To investigate the effect of temperature (293, 313, and $333 \mathrm{~K}$ ) on the uranium adsorption, the experiments were conducted at different initial concentrations of uranium. The results are given in Fig. 7. The adsorbed amount of uranium ions slightly increases with the increasing temperature from 293 to $333 \mathrm{~K}$. The observed increase in the adsorption capacity with the increasing temperature indicated that high temperatures improve U(VI) ions removal by adsorption on the hydroxyapatite sorbents. This effect suggested that the adsorption mechanism associated with removal of uranium ions on the hydroxyapatite sorbent involves a chemical process. This means that the adsorption process is of endothermic character (Zhu et al. 2011).

Table 4 The isotherm models parameters for the adsorption of U(VI) ions on the Ag-HAP and Ca-HAP, $\mathrm{R}^{2}$ - correlation, (for HAP see (Skwarek et al. 2017))

\begin{tabular}{|c|c|c|c|c|c|c|c|}
\hline \multirow[t]{2}{*}{ Model } & \multirow[t]{2}{*}{ parameter } & \multicolumn{2}{|l|}{$293 \mathrm{~K}$} & \multicolumn{2}{|l|}{$313 \mathrm{~K}$} & \multicolumn{2}{|l|}{$333 \mathrm{~K}$} \\
\hline & & Ag-HAP & Ca-HAP & Ag-HAP & Ca-HAP & Ag-HAP & Ca-HAP \\
\hline \multirow[t]{3}{*}{ Langmuir } & $\begin{array}{l}\mathrm{K}_{\mathrm{L}} \\
\left(\mathrm{dm}^{3} / \mathrm{mmol}\right)\end{array}$ & 375.09 & 318.54 & 744.2 & 2132.8 & 792.8 & 421.8 \\
\hline & $\begin{array}{l}\mathrm{q}_{\mathrm{m}} \\
(\mathrm{mmol} / \mathrm{g})\end{array}$ & 7.2 & 8.1 & 7.5 & 8.4 & 7.9 & 9.2 \\
\hline & $\mathrm{R}^{2}$ & 0.982 & 0.989 & 0.986 & 0.989 & 0.969 & 0.984 \\
\hline \multirow[t]{3}{*}{ Freundlich } & $\begin{array}{l}\mathrm{K}_{\mathrm{F}} \\
\left(\mathrm{dm}^{3} / \mathrm{mmol}\right)\end{array}$ & 0.0312 & 0.0279 & 0.0299 & 0.027 & 0.0328 & 0.0282 \\
\hline & $\mathrm{n}$ & 0.233 & 318.54 & 0.222 & 0.178 & 0.224 & 0.179 \\
\hline & $\mathrm{R}^{2}$ & 0.9464 & 0.259 & 0.9727 & 0.9909 & 0.9693 & 0.9453 \\
\hline \multirow[t]{4}{*}{ Dubinin-Radushkevich } & $\begin{array}{l}\mathrm{K}_{\mathrm{D}-\mathrm{R}} \\
\left(\mathrm{mol}^{2} / \mathrm{kJ}^{2}\right)\end{array}$ & $1.58 \times 10^{-9}$ & $1.66 \times 10^{-9}$ & $1.48 \times 10^{-9}$ & $1.26 \times 10^{-9}$ & $1.28 \times 10^{-9}$ & $1.15 \times 10^{-9}$ \\
\hline & $\begin{array}{l}\mathrm{q}_{\mathrm{m}} \\
(\mathrm{mmol} / \mathrm{g})\end{array}$ & 3.74 & 3.55 & 4.24 & 5.02 & 5.5 & 6.55 \\
\hline & $\begin{array}{l}\text { En } \\
(\mathrm{kJ} / \mathrm{mol})\end{array}$ & 10.25 & 17.35 & 18.4 & 18.9 & 19.8 & 19.8 \\
\hline & $\mathrm{R}^{2}$ & 0.9325 & 0.9895 & 0.9538 & 0.9880 & 0.9331 & 0.9834 \\
\hline
\end{tabular}


Table 5 Thermodynamic parameters for uranium adsorption on $\mathrm{Ag}$ $\mathrm{HAP}$ and Ca-HAP

\begin{tabular}{llllll}
\hline sorbent & $\begin{array}{l}\Delta \mathrm{H}^{0} \\
(\mathrm{~kJ} / \mathrm{mol})\end{array}$ & $\Delta \mathrm{S}^{0}(\mathrm{~kJ} /(\mathrm{mol} \cdot \mathrm{K}))$, & \multicolumn{4}{l}{$\Delta \mathrm{G}^{0}(\mathrm{~kJ} / \mathrm{mol})$} \\
\cline { 4 - 6 } & & $293 \mathrm{~K}$ & $313 \mathrm{~K}$ & $333 \mathrm{~K}$ \\
\hline Ag-HAP & 8.2 & 0.055 & -7.9 & -8.67 & -10.1 \\
Ca-HAP & 9.8 & 0.067 & -9.96 & -11.5 & -12.6 \\
\hline
\end{tabular}

The thermodynamic parameters such as Gibbs free energy $\left(\Delta \mathrm{G}^{0}\right)$, enthalpy change $\left(\Delta \mathrm{H}^{0}\right)$, and entropy change $\left(\Delta S^{0}\right)$ were estimated to evaluate the feasibility and the nature of adsorption process. The positive values of $\Delta \mathrm{H}^{\circ}$ for uranium removal on Ag-HAP and Ca-HAP (Table 5) confirm that the adsorption process was endothermic in nature. The negative $\Delta \mathrm{G}^{0}$ values indicate that the adsorption was feasible and spontaneous thermodynamically.

\section{Conclusions}

The nano-hydroxyapatite (HAP) and its modification AgHAP, Ca-HAP samples obtained using the wet method. It was found the specific surface areas for the samples decrease due to the presence of $\mathrm{U}(\mathrm{VI})$ which blocks the nano-hydroxyapatite pores. Substitution of $\mathrm{Ca}$ ions (CaHAP) and Ag ions (Ag-HAP) affected significantly the structure and properties of nano-hydroxyapatite and U(VI) adsorption. The quantities characterizing the double electrical layer were measured for the studied systems; The presence of $\mathrm{U}(\mathrm{VI})$ affects the size of surface charge density and zeta potential at the nano-hydroxyapatite and its modification/ electrolyte solution interface. The $\mathrm{pHpzc}$ point changes with the increasing $\mathrm{U}(\mathrm{VI})$ concentration shifting towards acidic value as a result of $\mathrm{U}(\mathrm{VI})$ accumulation on the surface. U(VI) ions affect the zeta potential value and compared to the initial electrolyte they decrease it in the whole $\mathrm{pH}$ range. At higher $\mathrm{pH}$ values evident decrease in the zeta potential with the increasing U(VI) ions concentration at constant $\mathrm{pH}$ is observed. The hydroxyapatite sorbent and its modification (Ag-HAP and Ca-HAP) has a high adsorption capacity. The theoretical sorption capacities determined by the Langmuir model were found to be $8.1 \mathrm{mmol} / \mathrm{g}$ for Ca-HAP and $7.2 \mathrm{mmol} / \mathrm{g}$ for Ag-HAP at $293 \mathrm{~K}$. The precipitation of mainly uranyl phosphates on the surface plays a decisive role in the sorption process besides sorption and ion exchange. The adsorption of U(VI) on the Ag-HAP and Ca-HAP follows well the pseudo-second-order kinetic model.

Open Access This article is distributed under the terms of the Creative Commons Attribution 4.0 International License (http://creativeco mmons.org/licenses/by/4.0/), which permits unrestricted use, distribution, and reproduction in any medium, provided you give appropriate credit to the original author(s) and the source, provide a link to the Creative Commons license, and indicate if changes were made.

\section{References}

Arey, J.S., Seaman, J.C., Bertsch, P.M.: Immobilization of uranium in contaminated sediments by hydroxyapatite addition. Environ. Sci. Technol. 33, 337-342 (1999)

Gilman, A.P., Villeneuve, D.C., Secours, V.E., Yagminas, A.P., Tracy, B.L., Quinn, J.M., Valli, V.E., Willes, R.J., Moss, M.A.: Uranyl nitrate: 28-day and 91-day toxicity studies in the sprague-dawley rat. Toxicol. Sci. 41, 117-128 (1998)

Ho, Y.S., McKay, G.: Pseudo-second order model for sorption processes. Process Biochem. 34, 451-462 (1999)

Janusz, W., Skwarek, E.: Study of sorption processes of strontium on the synthetic hydroxyapatite. Adsorption 22(4-6), 697-706 (2016)

Keith, L.S., Faroon, O.M., Fowler, B.A.: Uranium Berlin, M., Zalups, R.K., Fowler, B.A. (eds.): Handbook on the Toxicology of Metals. Academic Press, Denmark (2007)

Liu, Y., Cao, X., Hua, R., Wang, Y., Liu, Y., Pang, C., Wang, Y.: Selective adsorption of uranyl ion on ion-imprinted chitosan/ PVA cross-linked hydrogel. Hydrometallurgy. 104, 150-155 (2010)

Marczenko, Z., Balcerzak, M.: Spektrofotometryczne metody w analizie nieorganicznej. Wydawnictwo Naukowe PWN SA, Warszawa (1998)

Pang, C., Liu, Y., Cao, X., Hua, R., Wang, C., Li, Ch: Adsorptive removal of uranium from aqueous solution using chitosancoated attapulgite. J Radioanal. Nucl. Chem. 286, 185-193 (2010)

Sherman, D.M., Peacock, C.L., Hbbard, C.G.: Surface complexation of U(VI) on goethite. Geochim. Cosmochim. Acta. 72, 298-310 (2008)

Simon, F.G., Birman, V., Peplinski, B.: Uranium removal from groundwater using hydroxyapatite. Appl. Geochem. 23, 2137$2145(2008)$

Şimşek, S., Şenol, Z.M., Ulusoy, H.I.: Synthesis and characterization of a composite polymeric material including chelating agent for adsorption of uranyl ions. J. Hazar. Mater. 338, 437-446 (2017)

Skwarek, E.: Adsorption of $\mathrm{Cs}^{+}$at the hydroxyapatite/aqueous electrolyte interface. Ads. Sci. Technol. 33(6-8), 575-580 (2015)

Skwarek, E.: Application of silver tin research on hydroxyapatite, ashutosh tiwari. In: and Gerhardt, R.A. (eds.) Advanced Ceramic Materials. Scrivener Publishing LLC, Chap (2016)

Skwarek, E., Janusz, W.: Adsorption of Cd(II) ions at the hydroxyapatite/electrolyte solution interface. Sep. Sci. Technol. (Philadelphia) 51(1), 11-215 (2016)

Skwarek, E., Gładysz-Płaska, A., Bolbukh, Y.: Adsorption of uranyl ions at the nano-hydroxyapatite and its modification. Nanoscale Res. Lett. 12, 278-290 (2017)

Sprynsky, M., Kovaluk, I., Buszewski, B.: The separation of uranium ions by natural and modified diatomite from aqueous solution. J. Hazard. Mater. 181, 700-707 (2010)

Sun, X., Huang, X., Liao, X.P., Shi, B.: Adsorptive recovery of $\mathrm{UO}_{2}{ }^{2+}$ from aqueous solutions using collagen-tannin resin. J. Hazard. Mater. 179, 295-302 (2010)

Taffet, M.: Study of the Reactions Controlling the Mobility of Uranium in Ground and Surface Water Systems in Contact with Apatite, UCRL-TR-203891, U.S. Department of Energy by University of California, Lawrence Livermore National Laboratory under Contract W-7405-Eng-48. (2004) 
Ulusoy, H.I.: Determination of trace uranyl ions in aquatic medium by a useful and simple method. J. Radioanal. Nucl. Chem. 302(1), 497-504 (2014)

Yusan, S., Erenturk, S.A.: Adsorption equilibrium and kinetics of U(VI) on beta type of akaganeite. Desalination. 263, 233-239 (2010)

Zhu, W., Liu, Z., Chen, L., Dong, Y.: Sorption of uranium(VI) on $\mathrm{Na}$-attapulgite as a function of contact time, solid content, $\mathrm{pH}$, ionic strength, temperature and humic acid. J. Radioanal. Nucl. Ch. 289, 781-788 (2011)

Publisher's Note Springer Nature remains neutral with regard to jurisdictional claims in published maps and institutional affiliations. 